\title{
AUSENTES PRESENTES. REPRESENTACIONES DE INDÍGENAS Y AFRODESCENDIENTES EN IMÁGENES Y TEXTOS ESCOLARES. UNA MUESTRA ITINERANTE DEL MUSEO DE LAS ESCUELAS
}

María Cristina Linares

Universidad Nacional de Luján, Argentina 25cristinamaria@gmail.com

Silvia Alderoqui Centro Cultural de la Ciencia, Argentina silvia.alderoqui@yahoo.com.ar

Mariano Ricardes Museo de las Escuelas, Argentina marianoricardes@,gmail.com

\section{RESUMEN}

Los pueblos indígenas y afrodescendientes fueron invisibilizados del imaginario nacional cuando a fines del siglo XIX comenzó a construirse la idea de una "Argentina blanca". En este proceso la escuela desempeñó un papel importante por medio de la selección de sus contenidos, las efemérides, los actos escolares, los textos e ilustraciones de los libros de lectura, manuales y revistas para niños. A partir de la investigación sobre las colecciones de libros y documentos del Museo de las Escuelas hemos diseñado una muestra itinerante que quiere dar cuenta de cómo estos grupos sociales han sido excluidos develando estereotipos, prejuicios, presencias y ausencias. Las muestras itinerantes son un recurso excepcional para llegar a espacios y públicos que no pueden acceder a los museos. El fin principal es difundir la historia de la educación mediante un lenguaje específico, museográfico, que posibilite una lectura/vivencia crítica de los procesos históricos sobre la educación y al mismo tiempo permita mirar, leer, pensar, opinar, conversar, sentir junto a otros observando el presente para imaginar un futuro mejor.

Palabras clave: Museo. Muestra itinerante. Indígenas. Afrodescendientes.

\section{ABSENT PRESENT. REPRESENTATIONS OF INDIGENOUS AND AFRO- DESCENDANTS IN IMAGES AND SCHOOL TEXTS. AN ITINERANT SAMPLE OF THE SCHOOL MUSEUM}

\begin{abstract}
The indigenous and afro-descendant peoples were invisible from the national imaginary when the idea of a "white Argentina" began to be built at the end of the 19th century. In this process the school played an important role by means of the selection of its contents, the ephemeris, the school acts, the texts and illustrations of the reading books, manuals and magazines for children. From the research on the collections of books and documents of the Museum of Schools, we have designed a traveling exhibition that wants to show how these social groups have been excluded by revealing stereotypes, prejudices, presences and absences. The traveling exhibitions are an exceptional resource to reach spaces and audiences that cannot access to the museums. The main purpose is to disseminate the history of education through a specific language, museographic, which allows a reading / critical experience of the historical
\end{abstract}


processes on education and at the same time allow to look, read, think, comment, talk, feel together with others observing the present to imagine a better future.

Keywords: Museum. Traveling exhibition. Indigenous people. Afro-descendants.

\section{AUSENTES PRESENTES. REPRESENTAÇÕES DE INDÍGENAS E AFRODESCENDENTES EM IMAGENS E TEXTOS ESCOLARES. UMA AMOSTRA ITINERANTE DO "MUSEO DE LAS ESCUELAS}

\section{RESUMO}

Os povos indígenas e afrodescendentes foram invisibilizados do imaginário nacional quando no final do século XIX começou a ser construída a ideia de uma "Argentina branca". Neste processo, a escola desempenhou um papel importante através da seleção de seus conteúdos, as efemérides, os atos escolares, os textos e ilustrações dos livros de leitura, manuais e revistas para crianças. A partir da pesquisa sobre as coleções de livros e documentos do 'Museo de las Escuelas' organizamos uma exposição itinerante que quer mostrar como esses grupos sociais foram excluídos revelando estereótipos, preconceitos, presenças e ausências. As exposições itinerantes são um recurso excepcional para alcançar espaços e públicos que não têm acesso aos museus. O objetivo principal é divulgar a história da educação através de uma linguagem específica, museográfica, que permita uma leitura/vivência crítica dos processos históricos sobre a educação e, ao mesmo tempo, permita olhar, ler, pensar, comentar, conversar, se sentir observando o presente para imaginar um futuro melhor, ao lado de outros.

Palavras-chave: Museu. Exposição itinerante. Indígenas. Afrodescendentes.

\section{ABSENTS, PRESENTS. REPRESENTATIONS DES INDIGÈNES ET DES AFRO- DESCENDANTS DANS LES IMAGES ET LES TEXTES SCOLAIRES. UN EXPOSITION ITINÉRANT DU MUSEE SCOLAIRE}

\section{RESUME}

Les peuples indigènes et afro-descendants étaient invisibles de l'imaginaire national jusqu'a la construction, à la fin du 19ème siècle, de l'idée d'une «Argentine blanche». Dans ce processus, l'école a joué un rôle important lors de la sélection de son contenu, les éphémérides, les actes de l'école, les textes et les illustrations des livres de lecture, des manuels et des magazines pour les enfants. A partir de la recherche sur les collections de livres et de documents du Musée des Ecoles, nous avons conçu une exposition itinérante qui veut montrer comment ces groupes sociaux ont été exclus en révélant des stéréotypes, des préjugés, des présences et des absences. Les expositions itinérantes constituent une ressource exceptionnelle pour atteindre des espaces et des publics qui ne peuvent accéder aux musées. L'objectif principal est de diffuser l'histoire de l'éducation à travers une langue spécifique, muséographique, qui permet une lecture/expérience critique des processus historiques sur l'éducation et en même temps permettre de regarder, lire, penser, discourir, expérimenter a cote des autres en observant le présent pour imaginer un avenir meilleur.

Mots-clés: Musée. Exposition itinérante. Indigènes. Afro-descendants. 


\section{LAS MUESTRAS ITINERANTES}

Las muestras itinerantes son un recurso excepcional para llegar a espacios y públicos que no pueden acceder a los museos. En el caso del Museo de las Escuelas significa algo más, ya que no posee una sede propia donde en la actualidad pueda presentar exposiciones permanentes o temporarias. Por este motivo se diseñan exposiciones temporales en algunos espacios cedidos por la comunidad y se utilizan las muestras itinerantes.

El fin principal es difundir la historia de la educación mediante un lenguaje específico, museográfico, que posibilite una lectura/vivencia crítica de los procesos históricos sobre la educación.

Las muestras itinerantes están concebidas para abarcar un público amplio, en principio instituciones educativas de todos los niveles, aunque también pueden ser requeridas por centros culturales o sociales de diverso tipo. Son una experiencia de museo en otro espacio que sirve para ser recorrida solos o en grupo. Invitan a mirar, leer, pensar, opinar, conversar, sentir e imaginar.

En la actualidad el Museo cuenta con tres muestras en paneles de lona vinílica de $1,80 \mathrm{~m} \times 1 \mathrm{~m}:$

Lo que el borrador no se llevó

Educar en la memoria para construir el futuro

Con P de Patria

Las mismas se dan por préstamos y de manera gratuita por dos semanas a instituciones públicas y privadas de todo el país.

A estas muestras se le sumará la que motiva esta presentación: AUSENTES PRESENTES. Representaciones de indígenas y afrodescendientes en imágenes y textos escolares. 
Figura 1: Muestra itinerante: Ausentes Presentes. Representaciones de indígenas y afrodescendientes en imágenes y textos escolares.

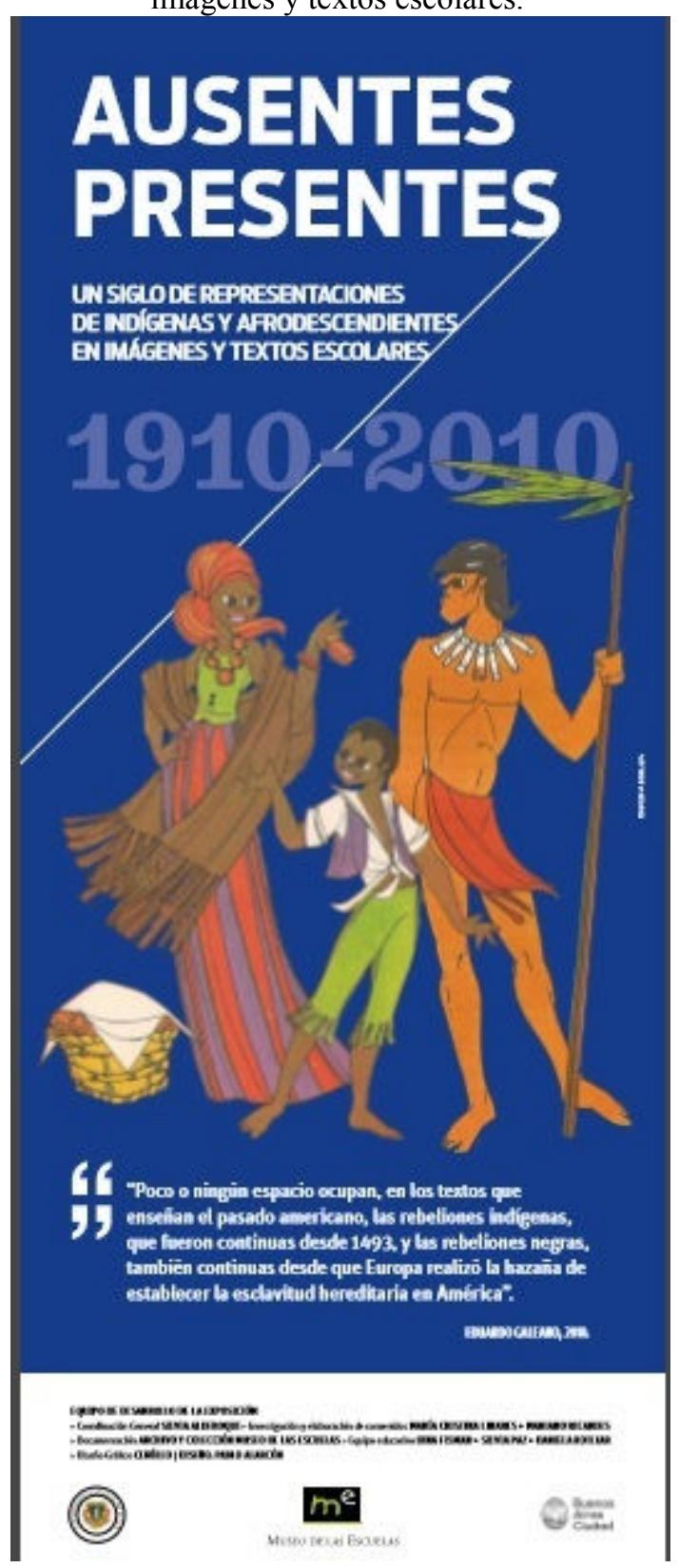

Fuente: Museo de las Escuelas.

\section{FUNDAMENTACIÓN}

El Museo de las Escuelas está directamente relacionado con la historia de la educación. Esa historia no puede quedar encerrada en los textos académicos, con lenguaje académico, que clausura un campo de conocimiento sobre sí mismo. Entendemos que hay conocimientos/saberes que consideramos socialmente significativos, y que es pedagógica y políticamente correcto y necesario socializar.

Desde el punto de vista de la Historia Social de la Educación, una tarea fundamental es

Rev. Iberoam. Patrim. Histórico-Educativo, Campinas (SP), v. 3, n. 2, p. 357-368, jul./dez. 2017 
la "desnaturalización" de los fenómenos sociales para "develar" su carácter construido, por eso los hechos educativos se presentan en el contexto socio-económico y político en el que se manifiestan. El cambio histórico no es una sucesión de etapas en donde la anterior es descartada en favor de una nueva, sino que existe una suerte de acumulación geológica de modificaciones que configuran un perfil en donde lo "viejo" perdura y opera sobre lo "nuevo".

La escuela es una entidad productora de una cultura específica, original. Por ello se valorizan las fuentes materiales de la historia de la escuela y los objetos son concebidos como un texto que puede ser leído, comprendido, interpretado en sus contextos de producción, circulación y apropiación, como "artefactos culturales" que encuentran significado y sentido en un proceso histórico.

En el marco temporal, la preocupación es fundamentalmente diacrónica, dando cuenta de la dinámica y los procesos, percibiendo a los fenómenos en su devenir y en su historia. No por ello dejamos de lado la mirada sincrónica de ciertos momentos históricos que son significativos, esto es enfocándonos en un periodo histórico determinado.

Sostenemos que la interacción de los visitantes con la información que provee una muestra y la que los visitantes intercambian entre sí dan un sentido de involucramiento en particulares oportunidades explicativas.

Respecto del patrimonio (material e inmaterial), lo entendemos como aquellos objetos, documentos, relatos o prácticas relacionadas con la historia escolar. A partir del momento en que se pone en valor el patrimonio, desde el museo hay que construir canales de comunicación, transferencia y diálogo entre los objetos y la comunidad, canales que están mediados por la interpretación que el museo realiza sobre el patrimonio. También sostenemos que la producción y el control del pasado es uno de los elementos decisivos en la conformación de identidades colectivas y los discursos museísticos y la producción historiográfica es una acción social contextuada y subjetiva, pero que la producción de ese conocimiento, que puede ser incompleto o fragmentario, no por ello implica arbitrariedad.

La "competencia narrativa", que es la que se pretende alcanzar mediante el aprendizaje histórico, cumple una función de orientación para la vida actual, dado que posibilita representarse el pasado de manera más clara, percibir el presente de manera más comprensible y adquirir una perspectiva del futuro más sólida. Este enfoque presenta al sujeto como participante activo de la historia, pues el hecho de operar bajo competencias narrativas le otorga la facultad de superar la historia como únicamente factual y estática, en la medida en que asimila el conocimiento histórico y lo hace circular como orientador de su vida diaria. A su vez, este proceso se revela como fruto de una socialización previa, pues cada individuo 
porta en sí una parte de la historia que puede ser digna de reflexión.

El tema a abordar por la muestra tiene sintonía con la actualidad. Por un lado, en algunos ámbitos, se están poniendo en cuestión la identidad y legitimidad de los pueblos originarios. Las perspectivas interculturales críticas señalan que no pueden dejar de tenerse en cuenta las relaciones de poder que atraviesan las sociedades y estructuran las vinculaciones entre los diversos grupos socio-culturales. No casualmente muchos grupos considerados "diferentes" son a la vez "pobres" o "excluidos". También incluyen el reconocimiento del derecho a la identidad cultural por parte de estos grupos. Para el caso de los afrodescendientes, a pesar de las nuevas perspectivas históricas, en las escuelas y en la sociedad en general se sigue sosteniendo el mito de la "Argentina blanca" e invisibilizando las comunidades afrodescendientes que existen en la actualidad y que continúan luchando por su visibilización. La historia de los afroargentinos está atravesada por mitos y verdades parciales que nos hicieron creer que murieron en las guerras de Independencia, del Paraguay y con epidemias como la fiebre amarilla. Se difundió una ideología racial que contó con la complicidad de la historia, de la falta de estadística y el desinterés de la sociedad.

Los discursos museísticos colaboraron en la configuración/reconfiguración de relaciones sociales, y particularmente interétnicas, desiguales, descalificadoras y discriminatorias

\section{Metodología de trabajo}

Para el desarrollo de una muestra itinerante se contemplan distintas etapas que no necesariamente se producen de manera secuencial ya que en varias oportunidades hay que volver y revisitar los pasos realizados:

- Investigación sobre el tema a tratar.

- Recopilación de documentos y materiales (en este caso textos escolares, láminas y fotos).

- Definición del relato o guion museológico.

- Diseño y elaboración de la muestra.

- Consultas en formato de talleres para el involucramiento de la comunidad en el diseño.

- Difusión de las muestras a través de redes sociales y correos a instituciones.

- Circulación de las muestras y asistencia a las instituciones. 


\section{Ideas centrales de la muestra AUSENTES PRESENTES}

La relación que se establece entre los contenidos sobre la historia de la educación en el museo y el público tiene ciertas particularidades, ya que compone un modo particular de saberes y experiencias educativas que no pueden ser adscritos directamente con la "academia" o con la "escuela".

AUSENTES PRESENTES podría referirse a todos y cada uno de los sectores olvidados o negados en los relatos oficiales de la historia escolar.

Enfrentamos oposiciones institucionales al inicio, también discusiones internas acerca de los contenidos, a quién iba dirigida y acerca de cómo presentar el material honestamente y sensiblemente. ¿Podrían participar otras voces en su elaboración? ¿O sólo los académicos que estudian el tema? ¿Cómo dar a conocer a una amplia comunidad educativa los resultados de investigaciones y tesis doctorales? ¿Cómo hacer una muestra que al mismo tiempo se convierta en un espacio para el intercambio democrático sobre los legados del prejuicio racial y el colonialismo? Queríamos que la experiencia de los receptores los llevara a hacerse preguntas tales como: ¿Por qué algunas personas piensan que el color de su piel los hace mejores que otros? ¿Por qué los "blancos" decidieron contar la historia ocultando a los indígenas y afrodescendientes?

Nos propusimos hacer visible la discriminación y el racismo encubierto en los textos e imágenes escolares, poniendo en valor materiales pasados por alto: láminas escolares, revistas infantiles, las ilustraciones de los manuales. Mostrar el otro lado de la Argentina de los "blancos" inmigrantes y españoles instalada desde los materiales de la escuela. Revelar la mirada colonial de la esclavitud y los pueblos indígenas. Instalar una narrativa de la duda y el conflicto. Comparar los adjetivos seleccionados, destacar los mensajes más fuertes: negro/blanco, raza moribunda.

Constantemente nos preguntamos qué significa hablar en nombre de otros y cómo darles la posibilidad de participar en las decisiones sobre contenidos o al menos de cuestionarlos para no caer en posturas paternalistas o en proyectos para destinatarios similares a nosotros.

El proceso de selección de las ideas que guiarían la muestra no fue simple. Intentamos construir una narrativa posible de ser transformada en una exposición itinerante. Con el título comenzamos planteando el tema de la invisibilidad, del borramiento, de la exclusión de las sociedades indígenas y afrodescendientes del relato de la historia escolar plasmado en textos e ilustraciones: VISIBLE INVISIBLE. Luego apelamos a juegos de palabras con la palabra 
NOSOTROS. LOS OTROS. NOS OTROS. A partir de las lecturas apareció la idea de aludir a una imagen conocida EL CRISOL INCOMPLETO. Decidimos finalmente que ese fuera el título de uno de los paneles. Fueron las imágenes anacrónicas de indígenas y afrodescendientes en los cuadernos y los libros escolares las que nos fueron llevando a la idea de ausencia y presencia, vinculada además con sus ausentes o presentes en la escuela y así llegamos a AUSENTES PRESENTES.

Luego de varios recorridos, de la posibilidad e imposibilidad de contar "todo" la propia selección nos llevó a privilegiar ciertos ejes.

\section{El mito de la Argentina "blanca"}

Las ideas racialistas de fines del siglo XIX y principios del XX construyeron el imaginario de un pueblo "blanco" formado a partir de inmigrantes europeos "descendidos" de los barcos dispuestos a mezclarse en un "crisol de razas". Estos conceptos sustentaron discursos escolares que invisbilizaron la presencia indígena y afrodescendiente o la colocaron en el lugar de los "otros", externos a la nación. Hasta fines del siglo XX, se hace referencia a los indígenas en relación a la llegada de los españoles. La conquista se relata como el "nacimiento" de la historia americana. Un acontecimiento en el que no se incluye la violencia y el exterminio, con pocas o nula referencias a la resistencia indígena. Los afroamericanos fueron arrancados de sus comunidades y traídos a América como mercancía. En los libros de lectura la condición de la esclavitud aparece poco y vacía de conflictos.

\section{Iluminaciones y opacidades}

En las últimas décadas, la gran diversidad de experiencias, prácticas y aspiraciones de los pueblos originarios y afroargentinos desafían y erosionan la imagen de la Argentina como nación "blanca" y “culturalmente homogénea". Sus luchas y demandas políticas contribuyen a la visibilización de la diversidad étnica y cultural y al reconocimiento de sus derechos por parte del Estado.

Los indígenas y afrodescendientes han dejado de ser una presencia ausente para convertirse en parte del mosaico socio-cultural nacional y de los debates políticos que buscan definir sus alcances y sus límites.

Desde mediados de la década de1980 algunos libros escolares comenzaron a reflejar estos cambios, aunque todavía perduran opacidades y prejuicios. A las nuevas y viejas 
modalidades de representación se suman los textos educativos producidos por las comunidades incluyendo su propia voz en el discurso escolar.

\section{Actos escolares}

Los actos escolares del 12 de octubre y del 25 de mayo siempre fueron un espacio de visibilización del imaginario social acerca de los indígenas y los afrodescendientes en la historia argentina. Allí las representaciones de los libros escolares toman forma física, cuerpo y voz e involucran a maestros, alumnos y familias.

Actualmente se observan cambios en los discursos y las representaciones que responden al reconocimiento de la diversidad étnica y cultural de la Argentina. Sin embargo en muchas escuelas sobreviven visiones excluyentes y estigmatizadoras.

Los afrodescendientes son representados en los actos escolares del 25 de mayo como vendedores ambulantes o ilustrando tareas domésticas coloniales. Hasta principios del siglo XXI no hay personajes que cuenten lo que sufrieron y cómo resistieron como esclavos ni su participación en las guerras de independencia.

En la actualidad en algunas escuelas la celebración del 25 de mayo es una ocasión para reflexionar sobre la libertad. Y en ese marco se visibiliza a los "negros" como esclavos. Los indígenas sólo aparecen en los actos escolares para el 12 de octubre, el antes llamado "Día de la Raza" y hoy en la Argentina "Día de la Diversidad Cultural Americana". En la imagen ingenua de un desembarco feliz los niños representan a los indígenas alegres y sumisos caracterizados con plumas, trajes de arpillera y ponchos.

\section{El mito de la extinción}

Muchos textos e ilustraciones escolares de la primera mitad del siglo XX muestran a los indígenas y a los afrodescendientes como últimos supervivientes de etapas evolutivas superadas por los "blancos". Se basan en las clasificaciones raciales de fines del siglo XIX que postulan una superioridad de la población "blanca". De esta manera la ciencia justificaba el racismo. A partir de las campañas militares contra los indígenas en los siglos XIX y XX, Argentina se presenta como "un país sin indios". Por extinción o asimilación, los indígenas son representados como pueblos destinados a desaparecer. La violencia sobre los pueblos originarios se justifica por los valores de la "civilización blanca" contra la "barbarie indígena”. 
En la construcción del Estado Nacional tampoco hubo lugar para los afroargentinos. La mayoría de los textos escolares hasta la actualidad omiten la participación de los "negros" en la vida nacional. Esto refuerza tácitamente el mito de que las epidemias y guerras del siglo XIX hicieron desaparecer a los descendientes de africanos. Esta invisibilización funciona como otra expresión del racismo.

\section{Confinados en el tiempo}

Los libros escolares confinaron a los indígenas y a los afrodescendientes en un tiempo remoto, el período previo a la conformación del Estado nacional.

Desde principios del siglo $\mathrm{XX}$, los indígenas fueron presentados como restos arqueológicos, como "antiguos habitantes" sin vínculo con la cultura y la historia nacional. Los verbos que hablan de sus viviendas, vestimenta y alimentación siempre se conjugan en tiempo pasado. Este modo de aparición-desaparición se constituyó al mismo tiempo en que eran incorporados a la fuerza en las reducciones estatales y como trabajadores en los ingenios, obrajes y el servicio doméstico.

Las "negras y los negros" son representados únicamente en la época colonial realizando tareas domésticas y de venta ambulante. En pocos casos se hace referencia a ellos como milicianos en las guerras de la independencia. Su condición de esclavos se mantiene invisible y no hay información sobre su vida cotidiana y cultural después de esta época.

\section{Estereotipos}

Hasta finales del siglo XX las lecturas sobre afrodescendientes e indígenas se ilustran con imágenes estáticas, simplificadas y ambivalentes. De esta manera aparecen convertidos en personajes y se invisibiliza su humanidad y complejidad.

Los indígenas son expuestos como salvajes, en imágenes que refieren a la brutalidad y el miedo, a expresiones amenazantes y multitudes guerreras. También son representados dóciles y sumisos, realizando actividades tranquilas en la naturaleza. Los "negros y las negras" siempre se muestran en situaciones ingenuas y risueñas o de amenaza donde la negritud es mala y es necesario "blanquearla". En estas lecturas el color negro se convierte en un estigma que aún hoy alcanza a los dichos, a los objetos, a las acciones y a las personas. 


\section{REFLEXIONES FINALES}

En los museos o en las muestras itinerantes que diseñamos no podemos evaluar procesos de construcción del sentido del tiempo histórico, ni es nuestro propósito evaluar adquisición de contenidos, como sí lo puede hacer la educación formal escolarizada. No obstante, esos momentos en que los visitantes "viven" el museo o la muestra pueden contribuir, junto a otras instituciones culturales, a lo que consideramos "cultura histórica", esa parte de la percepción, de la interpretación, de la orientación y del establecimiento de una finalidad que toma al tiempo como factor determinante de la vida humana (RÜSEN, 2009).

La muestra AUSENTES PRESENTES, ha sido consultada con algunos especialistas y representantes de las comunidades afroargentinas e indígenas, tarea que continuará hasta llegar a la versión definitiva.

Comprendemos que la relación pedagógica que se establece entre visitante y museo es una acción social y cultural, un "acto participativo" en el que el visitante "toma parte" y "es parte" de entornos educativos. El aprendizaje de los sujetos se define no solo sobre la base de competencias y capacidades individuales, sino sobre la compleja relación entre sujeto y situación. Cobra relieve la figura de un sujeto constituido en prácticas culturales por procesos de apropiación recíproca entre sujeto y cultura. Proceso que no es simétrico y que deja al descubierto el carácter inevitablemente político de toda experiencia educativa, en la medida en que produce cursos específicos de desarrollo u obtura otros.

Esta es una muestra sobre omisiones y relatos contados que esperan multiplicarse para salir de la encrucijada y compartir autoridad y autoría.

\section{BIBLIOGRAFÍA}

ALDEROQUI, Silvia; PEDERSOLI, Constanza. La educación en los museos. De los objetos a los visitantes. Buenos Aires: Paidos, 2011.

; LINARES, M. C. Los visitantes como patrimonio. El Museo de las Escuelas, primeros 10 años. Buenos Aires: Ministerio de Educación GCBA, 2012.

; _ (coords.). Participación y representación de los visitantes en el Museo de las

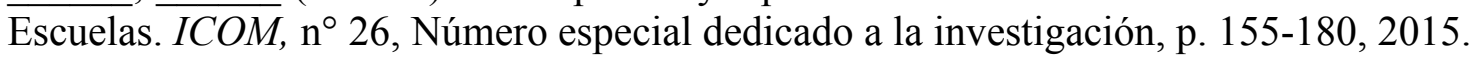

FALK, J.; DIERKING, L. The museum experience. Washington: Whalesback Books, 1992.

JELIN, Elizabeth. Los trabajos de la memoria. Madrid: Siglo XXI, 2002. 
KAROL, Mariana. La transmisión: entre el olvido y el recuerdo, entre el pasado y el futuro. En: Una ética en el trabajo con niños y jóvenes. La habilitación de la oportunidad. Buenos Aires: Novedades Educativas - Cem, 2004.

LEINHARDT, G. Y; CROWLEY, K. The museum learning collaborative. http:||museumlearning.com|default.html

LINARES, María Cristina. Educar con los objetos. Museos pedagógicos en la historia de la educación argentina (1880-2009). Tesis de doctorado, Universidad Nacional de Luján, Mimeo, 2012.

; RICARDES, Mariano. El lado oscuro de la negritud: Las representaciones de los afroamericanos en los libros de lectura escolares (1895-2000). En: Actas de las Segundas Jornadas de Estudios Afrolatinoamericanos del GEALA. Florencia Guzmán y Lea Geler (Coordinadoras). Instituto de Historia Argentina y Americana “Dr. Emilio Ravignani” (UBA). Museo Histórico Nacional, 2011.

RICARDES, Mariano. Acerca del tiempo y los bienes patrimoniales. En: Actas del XIX Encuentro educativo El museo y la escuela, Archivo Histórico y Museo Histórico del Banco de la Provincia de Buenos Aires - ICOM, 2009.

RÜSEN, Jörn. ¿Qué es la cultura histórica?: reflexiones sobre una nueva manera de abordar la historia. [Unpublished Spanish version of the German original text in K. Füssmann, H.T. Grütter and J. Rüsen, eds. (1994): Historische Faszination. Geschichtskultur heute. Keulen, Weimar and Wenen, Böhlau, p. 3-26, 2009.

Recebido em: 01 de dezembro de 2017 Aceito em: 15 de dezembro de 2017 